\title{
Tomás Halík, Paciencia con Dios, Herder, Barcelona 2014, 245 pp.
}

Tomás Halík es un sacerdote checo, ordenado furtivamente durante el régimen comunista. Durante esa etapa desarrolla clandestinamente su actividad pastoral y participa activamente en la resistencia cultural impartiendo cursos en la «universidad volante» o publicando samizdats (copia y distribución de literatura prohibida, p. 22). Cuando Chequia alcanza la libertad se desempeñó como profesor universitario, consejero de Václav Havel y secretario de la Conferencia Episcopal. San Juan Pablo II lo nombra consejero del ahora extinto «Pontificio Consejo para el diálogo con los No Creyentes» y en 2014 recibe el Premio Templeton. Chequia es uno de los países con más alto porcentaje de ateos, de forma que en su labor tanto pastoral como intelectual ha mantenido un ininterrumpido intercambio con ellos.

En el presente libro - condecorado como el mejor libro de Teología Europea 2009/10 - , intenta desarrollar «el motivo de Zaqueo» de modo análogo «a como Henri Nouwen dedicó su conocido ensayo a otro relato bíblico, el retorno del hijo pródigo» (p. 18). Zaqueo es arquetipo de aquel que mira a Jesús de lejos, sin comprometerse, y que necesita ser llamado expresamente por su nombre para acercarse a Él. A través de esta meditación va pasando revista a la actitud de la Iglesia con «los que están lejos», los que «no quieren comprometerse», y en definitiva, lo ateos, los eternos buscadores que nunca terminan de «encontrar» a Dios.

Halík, al realizar este trabajo, enriquecido no solo por una reflexión a la par erudita e interesante, sino por la experiencia pastoral propia, ofrece perspectivas novedosas y en cierto sentido sorprendentes, sobre el modo de valorar los fenómenos del ateísmo, agnosticismo o la simple indiferencia religiosa. En el capítulo VI, por ejemplo, ofrece una curiosa taxonomía sobre diversas formas de ateísmo: el «ateísmo de la pasión» (que a su vez tiene dos variantes: «la pasión de la protesta» $\mathrm{y}$ «la pasión de la búsqueda») y el «ateísmo de la indiferencia», correlativos ambos a sendas formas de fe: «la fe perezosa» y la fe como «búsqueda de Dios incesante y apasionada» (p. 128). El cambio de perspectiva permite acercarse a los ateos, más que como antagonistas, como a hermanos, con quienes tenemos la responsabilidad de construir en conjunto una sociedad humana digna, y quienes se encuentran, quizá sin ser conscientes de ello, muy dentro del Corazón de Dios.

Sus fuentes son de lo más variopintas. Fundamentalmente se apoya en Nietzsche y santa Teresita, entre los que desarrolla un atrevido paralelismo. Pero además encontramos desde Joseph Ratzinger a san Juan Pablo II, desde Hans Urs von Balthasar a Johann Baptist Metz o Karl Rahner, desde el maestro Eckhart a Lutero, desde Orígenes, san Agustín, san Juan de la Cruz a san Ignacio de Loyola, de Chesterton a Shakespeare, de Carl Gustav Jung a Sigmund Freud,

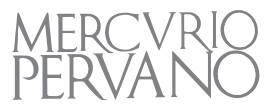


de Gianni Vattimo a Slavoj Zizek. Su propuesta intelectual va en la línea de la teología negativa, apofática, según la cual «si comprendiste, no es Dios», pues «Dios es siempre más grande, semper maior, como nos enseña la mística ignaciana» (p. 76).

Para él tender puentes de comunicación con los ateos y cambiar de perspectiva es de crucial importancia para el mundo actual. «Estoy convencido de que no hay ahora nada más importante en nuestro mundo que encontrar un camino entre la Escila del fundamentalismo religioso y el Caribdis del secularismo fanático» (p.183). En este sentido engloba dentro del conjunto «ateísmo» a todos aquellos que están «lejos de Dios»; en ocasiones como en «su búsqueda», pero también «contra Él». Se refiere de modo indistinto al ateísmo en general, al «humanismo secular» o a la «tradición laica»; es decir, todos caben dentro de «los que están lejos», con quienes hay que intentar dialogar y establecer puntos de contacto.

¿En qué consiste esta nueva mirada hacia el fenómeno del ateísmo? Podría sintetizarse su postura en dejar de verlo como antagonista, como el enemigo, y comenzar a considerarlo como a un compañero del cual algo se puede aprender. Es bastante diferenciado el papel que el ateísmo está llamado a desempeñar en el mundo de hoy, y por lo tanto, la aportación que puede suponer a la fe católica.

Esta idea puede parecer paradójica - el autor es consciente de su fascinación por la paradoja - pero por ello mismo es sugerente: Por un lado el ateísmo moderno ha realizado una dura criba de la fe, de la cual el catolicismo debe renacer más fuerte. Por otra, la fe católica, así como en la antigüedad supo hacer propios los auténticos valores de las culturas con las que se encontró, de la misma forma en la modernidad debe integrar todo cuanto de verdadero y de valioso pueda aportarle el secularismo humanista y ateo. En este sentido dos citas son suficientemente elocuentes. La primera: «Sería una negligencia punible que el cristianismo no utilizase en su provecho el hecho de haber sido -como ninguna otra religión - expuesto durante la Edad Moderna a los crisoles purificadores de la crítica atea» (p. 17). La segunda: «Sí, tengo que confesar que no me agradaría permitir que, el día que al ya viejo ateísmo de la modernidad europea lo cubra el manto del olvido, el cristianismo no hubiese conquistado y apropiado para sí lo que en él era de oro, honesto y sincero, aunque fuese una verdad incompleta» (p. 16).

Ahora bien, el ateísmo en realidad, según el análisis de este autor, guarda una misteriosa pero real simetría con la religiosidad. De hecho, constituye una especie de religiosidad y es a un tiempo antídoto de la religiosidad superficial. «El ateísmo y el fundamentalismo religioso o el entusiasmo de una fe demasiado fácil se parecen de manera llamativa en lo rápido que consiguen dar por resuelto el misterio al que llamamos Dios» (pp. 11-12) ¿Cuál sería la diferencia entre ambos? «La paciencia es lo que considero la principal diferencia entre la fe y el ateísmo» (p. 11). De hecho, a eso se reduce el problema del ateísmo: «No 
digo a los ateos que no tienen razón, sino que no tienen paciencia; afirmo que su verdad es una verdad incompleta» (p. 16). ¿Cuál sería «su verdad»? La experiencia del ocultamiento de Dios...

El hilo conductor de toda esta meditación sobre la figura de Zaqueo, es decir, de aquellos que con una cierta curiosidad miran a Jesús de lejos sin querer ser abiertamente reconocidos, es la paciencia. Pero una noción de paciencia enriquecida, que a la postre viene a hilvanar las virtudes teologales y a ser la diferencia decisiva entre religión y ateísmo. «La fe, la esperanza y el amor son tres aspectos de nuestra paciencia con Dios; son tres formas de asumir la experiencia del ocultamiento de Dios. Ofrecen, por ello, un camino completamente diferente tanto del ateísmo como de la credulidad superficial» (p. 13).

Quizá es pertinente precisar el significado de algunos términos recurrentes y claves en la obra de Halík, aunque ello suponga, obviamente, una interpretación. Por «paciencia con Dios» puede entenderse la «no precipitación», el «saber esperar confiadamente», «el no impacientarse por exigir una respuesta inmediata y unívoca a los misterios de la existencia o de la fe», como pueden ser la experiencia del mal o del dolor. Precisamente estas realidades: el mal, el dolor, el sufrimiento del inocente constituyen el fundamento de lo que llama «ausencia», o más suavemente, «ocultamiento de Dios», que vienen a ser sinónimos, con algunas diferencias de matiz. La «ausencia de Dios» denota una carencia más profunda en quien lo experimenta que el simple «ocultamiento». El «ocultarse» implica saber que Dios está, pero no saber dónde, viviendo una especie de juego, que para algunos puede resultar macabro. En cambio la «ausencia» denota la orfandad total, la falta de algo considerado necesario, pero que se sabe no está. No hay en este sentido juego, más bien una tragedia. Sin embargo, el fundamento de ambos términos, que el autor usa de modo intercambiable, es la experiencia del mal en el mundo y la consecuente no evidencia de Dios.

Halík se muestra a un tiempo cercano con los ateos y crítico con la religiosidad superficial, o con la fe excesivamente segura de sí misma, y por eso mismo, cerrada. Busca mostrar cómo en realidad lo esencial es la actitud de búsqueda, la cual puede ser común a creyentes y ateos. De esta forma, la existencia del ateísmo constituye una llamada para el creyente, para que no se considere en ningún momento «dueño» del «Misterio», sino siempre en camino. «Las respuestas suelen conllevar la tentación de terminar el proceso de nuestra búsqueda, como si el objeto de la conversación fuese un problema... y este hubiese sido ya resuelto. Pero con la siguiente pregunta se trasluce de nuevo la profundidad inagotada del misterio. Repitamos una y otra vez: la fe no trata de problemas, sino más bien del misterio, y por eso no podemos abandonar nunca el camino de la búsqueda y la interrogación» (p. 27).

Para superar esa superficialidad religiosa Halík propone una curiosa terapia: tomar en serio el ateísmo, hacer propia su actitud de búsqueda, intentar aprender aquellas disposiciones que nos recuerden que siempre, delante de Dios, estamos frente al «Misterio». «La «fe madura» sigue siendo para nosotros

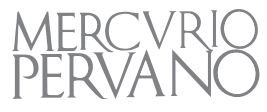


una tarea inacabada (precisamente para culminarla necesitamos tomar en serio la experiencia del ateísmo), y no algo de la que ya disponemos y que podamos considerar «de nuestra propiedad»» (p. 61).

¿A qué se refiere con «la experiencia del ateísmo»?, ¿cuál es la perspectiva nueva que el ateísmo puede aportar a la fe? Precisamente la experiencia de la ausencia de Dios. En este sentido, Halík hace una de sus habituales comparaciones o paralelismos audaces. ¿Qué tienen en común Jesús en la Cruz cuando exclama: «Dios mío, Dios mío, ¿por qué me has abandonado?», santa Teresita de Jesús en las vísperas de su muerte, o Nietzsche en La gaya ciencia? Que los tres experimentan, si bien de modo distinto, la ausencia de Dios. Pero es precisamente esa sensación de ausencia la que nos impulsa imperiosamente a buscar a Dios: «Pocas cosas señalan hacia Dios con tanta intensidad y claman por Él con tanta urgencia como la experiencia de su ausencia» (p. 15). «Sin la dolorosa experiencia del «mundo vacío de Dios» nos será difícil entender el sentido de la búsqueda religiosa» (p. 16).

Lo que para muchos constituye prueba evidente de la inexistencia de Dios, Halík lo convierte en presupuesto imprescindible de la «fe madura» y en punto de partida del diálogo con los no creyentes. «Estoy convencido de que una $f e$ madura debe incorporar dentro de sí esas experiencias con el mundo y con Dios, que algunos llaman "muerte de Dios" o - menos dramáticamente- "silencio de Dios"» (p.16). Y es precisamente este tomar en serio los planteamientos ateos y secularistas lo que constituye un buen comienzo en el diálogo entre creyentes y ateos. No busca tanto enseñar como aprender y acompañar. «Nuestra cercanía con los que buscan tiene que enseñarnos a nosotros apertura; no podemos pensar solamente en que tenemos que instruir y adoctrinar: podemos aprender mucho de ellos... Poder atisbar por un momento cómo se ve a Dios desde la perspectiva de los que buscan, los que dudan, los que se interrogan... ¿no es esto una experiencia religiosa nueva, necesaria y útil?» (p. 39).

El ateísmo en consecuencia nos vacuna frente a una fe simplista que elude sistemáticamente los planteamientos críticos de la modernidad, o que se desarrolla a espaldas de ella, viviendo de ingenuas ensoñaciones. «También el ateísmo puede ayudar a "preparar el camino del Señor», puede ayudarnos a purificar nuestra fe de «ilusiones religiosas». No podemos, sin embargo, dejarle la última palabra, como hace la gente impaciente» (p. 17). Obviamente no hay que «quedarse allí»; el ateísmo señala un problema, el cual es resuelto desde la «paciencia con Dios».

Este cambio de actitud tiene dos consecuencias concretas en el planteamiento del autor: el modo de entender su misión como sacerdote, y la importancia que reviste este diálogo para el futuro de la sociedad. Sobre el primer aspecto afirma: «¿Qué significa acercar hoy a alguien a Cristo y a través de Cristo a Dios? No pienso que sea tan fácil como les parece a algunos cristianos entusiastas. El sacerdote no puede convertirse en un agitador, un propagandista, un hombre 
de lemas simples y hábil manipulación de los demás; su rol es más bien acompañar a otros, con paciencia y gran respeto a cada uno, guiar, iniciar, llevar hasta el umbral del misterio, que conquistarlos al estilo con que los políticos o los comerciantes captan el interés para su mercancía más reciente» (p. 29). De esa consideración general pasa a una descripción de cómo entiende él personalmente su misión sacerdotal: «Siento que estoy aquí primordialmente para ofrecer una cercanía comprensiva a aquellos que tienen obstáculos insuperables para alinearse en las masas exultantes y bajo los estandartes desplegados de cualquier color; aquellos que mantienen las distancias» (p. 25). Halík tiene debilidad por los Zaqueos.

Buscar la cercanía comprensiva y el acompañamiento de los que están lejos constituye la línea de acción vigente en la Iglesia: «Un intento grandioso de la Iglesia católica de acercarse al mundo moderno y hacer así más legible y cercano al hombre contemporáneo a Cristo y su mensaje fue... el Concilio Vaticano II. Este se puso como meta precisamente superar el abismo entre la Iglesia y «esos otros», instaurar el diálogo con la cultura secular moderna y con el humanismo secular, con las restantes Iglesias cristianas, con los creyentes de religiones no cristianas y con los agnósticos y ateos... La novedad y especificidad de este concilio consistieron sobre todo (en que) ... propuso otra terapia. La Iglesia debía ante todo hacerse solidaria con el hombre contemporáneo» (p. 79).

Esta solidaridad no solo es de interés para la Iglesia y los ateos, sino para toda la sociedad, por lo menos occidental. Así entramos en la segunda consecuencia, de corte más general, sobre el cambio de actitud frente a los ateos. Es de vital importancia buscar lo que nos une en lugar de acentuar la división. «La sociedad democrática no puede mantenerse sin el trabajo conjunto de los cristianos y los humanistas laicos: ambas tradiciones contienen un gran potencial moral, muy necesario, y sería una gran desgracia que derrochasen sus energías en disputas entre ellos» (p. 106). Más que anular energías o perder tiempo en estériles confrontaciones, es preciso trabajar unidos. Solo así podrá conjurarse, por ejemplo, el peligro latente que supone el fundamentalismo religioso. «Si Occidente puede convencer de alguna forma a la parte más razonable del mundo islámico de que no es «el imperio de Satanás», es convirtiéndose en la demostración práctica de que la religión y la sociedad secular pueden no solo vivir en paz la una con la otra, sino, además, enriquecerse mucho mutuamente» (p. 106). El fruto de ese esfuerzo no solo es un mayor nivel de diálogo y por tanto de paz, sino una maduración en la fe. «Pienso que el mayor examen de madurez será ahora para nosotros, los cristianos, la medida de nuestra capacidad y nuestra disposición a ver en los humanistas laicos de hoy no a nuestros enemigos, sino a nuestros hermanos, aunque sea a menudo airados y no siempre agradables... No es tiempo para reproches, sino tiempo de conversión y búsqueda de la mutua compatibilidad» (p. 110).

Ahora bien, pareciera que para Halík los ateos son «los buenos de la película». No es tan sencillo. Desde el principio señala que el ateísmo supone una 
carencia, una falta de paciencia con Dios, y que aun pudiendo aportarnos muchas cosas, no debemos dejarle la última palabra. Muestra también, acertadamente, algunas de sus profundas incoherencias o faltas de solvencia intelectual. Por ejemplo, frente a quienes justifican su rebelión contra Dios por la presencia del mal y el dolor en el mundo, señala: «Sí, tras la retórica del odio suelen estar el dolor, la herida; las apasionadas «acusaciones a Dios» suelen ser un grito de dolor y de protesta. El ser humano siente dolorosamente la «injusticia» y lo «inmerecido» del mal, que le tocó a él mismo o a otros, y protesta contra él. Pero llegamos aquí a la paradoja oculta de este ateísmo que protesta apasionadamente: el mismo presupuesto de que en el mundo hay un orden justo previamente dado, lleno de sentido, en el que los buenos son premiados y solo los malos castigados, es -como reconoció Nietzsche - un presupuesto religioso. Sería, después de todo, absurdo que la protesta contra el quebrantamiento del orden la elevase un hombre que niegue la propia existencia de ese orden. Si no admitiésemos ese orden y no creyésemos en su existencia, ¿por qué tendríamos entonces que detenernos ante el mal y la injusticia: con respecto a qué podría ser cualquier acontecimiento «injusto»o «malo»?» (p. 131).

Halík señala cómo los «cimientos del ateísmo» en realidad se identifican con la experiencia histórica del mal. «Momentos semejantes «lejos de todos los soles», que en el gran escenario de la historia designamos con símbolos como «Auschwitz», «Gulag», «Hiroshima», «11 de septiembre» o «Civilización de la Muerte», y en el plano cotidiano de los destinos individuales con las palabras depresión o crisis, son para muchos «el cimiento del ateísmo»» (p. 15). No le da la razón al ateísmo, lo comprende; no lo exalta, pero tampoco lo banaliza; lo toma en serio, no piensa que es una simple insuficiencia moral o intelectual. Al mismo tiempo, repensar la fe desde el ateísmo le sirve para atisbar más aún su profundidad «¿Qué otra cosa es la fe sino esa apertura acogedora al ocultamiento de Dios, ese valiente sí (o al menos anhelante «quizá») de nuestra esperanza en el profundo silencio del silencio de Dios, esa llamita tenaz que brota una y otra vez de las cenizas de la resignación hasta en la noche más larga, oscura y fría? En el cristianismo, no se puede separar la fe y la esperanza..., y la paciencia es su característica y su fruto comunes» (p. 233).

Quizá lo más novedoso o audaz de la exposición sea el intento que hace Halík por mirar a los ateos desde la perspectiva de Dios, e intentar entender también de esa forma su misión peculiar en el designio divino y el reto que suponen para nuestra fe. Cita, en este sentido, a Simone Weil: «Una de las más preciosas alegrías del amor terreno, servir al amado sin que este lo sepa, es posible en el caso de Dios solo mediante el ateísmo» (pp. 233-234, citando: Simone Weil, El conocimiento sobrenatural, Madrid, Trotta, 2003). Es decir, los ateos no son «cristianos anónimos» en el sentido rahneriano, que tantos estragos ha causado, pero son, sin duda, amados por Dios. No solo amados, sino que Dios actúa en ellos y se manifiesta en ellos a través de las obras buenas que eventualmente realicen, sin ser ellos conscientes claro está. Se convierten, sin quererlo, en ins- 
trumentos de Dios, y el hombre de fe puede también por eso - y no solo por la imagen y semejanza - descubrir a Dios oculto en ellos mediante la contemplación. Halík denota una fuerte influencia de Rahner, pero no juega en los límites de la ortodoxia.

Paciencia con Dios finaliza sin concluir. Deja abierta la puerta a la esperanza, al misterio de la omnipotencia y el amor divinos. « ¿Se oculta Dios en los ateos a ellos mismos y al mundo, para acabar al final de los tiempos con este juego al escondite de amante romántico y preparar a los ateos la sorpresa de que Él estaba presente en ellos, en sus vidas, de que Él a través de ellos y ellos con Su fuerza (escondida) hacían el bien..., y se verá a la vez también sorprendido y complacido el mundo (incluidos los cristianos) al conocer que aquello con lo que a veces les sorprendían los ateos era en realidad un don y un mensaje cifrado de Dios, que era su secreta presencia en ellos? Sí, creer en Dios, al que no vemos, significa también como mínimo esperar que está incluso allí, donde no lo vemos, y con frecuencia allí, donde estamos convencidos a pie juntillas de que no está ni puede estar» (p. 234).

P. Mario Arroyo 